\title{
COMPARATIVE ANALYSIS OF DAMAGE CRITERIA FOR SCREW ROLLING USING COMPUTER SIMULATION
}

\author{
M. M. Skripalenko1, B. A. Romantsev², S. P. Galkin³, M. N. Skripalenko³, A. V. Danilin³ \\ ${ }^{1}$ MIP Rolling Mill LLC (Moscow, Russia) \\ 2 Istok ML LLC (Moscow, Russia) \\ ${ }^{3}$ National University of Science and Technology "MISiS” (Moscow, Russia)
}

E-mail:mms@misis.ru; tfsmn@yandex.ru

AUTHOR'S INFO

M. M. Skripalenko, Cand. Eng., Associate Prof., Metal Forming Dept.,

B. A. Romantsev, Dr. Eng., Prof., Metal

Forming Dept.;

S. P. Galkin, Dr. Eng., Prof., Metal Forming Dept.,

M. N. Skripalenko, Cand. Eng., Associate Prof., Metal Forming Dept.,

A. V. Danilin, Senior Lecturer, Metal Forming Dept.

\footnotetext{
Key words:

screw rolling, two-high rolling mill, damage criterion, computer simulation, feed angle, Mannesmann effect.
}

\author{
A B S T RACT
}

Two-high screw rolling of billets was carried out using a MISIS-130D rolling mill. AISI 321 stee billets were deformed with feed angles of rolls of $6^{\circ}, 12^{\circ}, 18^{\circ}$ and $24^{\circ}$. The diameter reduction was $17 \%$, with the initial billets' diameter being $60 \mathrm{~mm}$. An axial fracture, the so-called Mannesmann effect, of the billets was observed after screw rolling. The experimental rolling was simulated using QForm finite element method software. Initial and boundary conditions were set in concordance with the experimental rolling. Several damage criteria were used for fracture prediction during computer simulation. The results of computer simulation of fracture prediction were compared with the billets fracture after screw rolling for stationary and non-stationary stages. The most effective parameter (in terms of fracture prediction) is triaxiality. The distribution of this parameter showed that the higher the feed angle value is, the lower the fracture risk is. Notably, the risk of fracture is lower at a stationary stage compared with the same risk of fracture at a non-stationary stage; the listed trends agree with experimental rolling results. The Oyane, Ayada, Brozzo, and Cockroft-Latham Normalized criteria are partly effective. These criteria are ineffective for fracture prediction 6 degrees feed angle of rolls because they showed that fracture is most probable at the billet's surface, which contradicts the experimental rolling results. All these criteria are partly effective when predicting a less fracture risk at a stationary stage compared with the same criteria at a non-stationary stage or when predicting a decrease of fracture with increasing the rolls feed angle.

\section{Introduction}

Screw rolling is widely used in metallurgical manufacturing [1-3]. An axial fracture of billets may occur at some forming modes during two-high screw rolling [4]. It is noticed that an axial fracture creates plug "self-centering" during two-high screw piercing [5]. The FEM (Finite Element Method) computer simulation is used to predict fracture during two-high screw rolling. The DEFORM FEM software was used by the authors of [6] to estimate an axial fracture, the so-called Mannesmann effect, during two-high screw rolling by using billets with an axial hole. Computer simulation of an axial fracture in front of the plug's nose was done in [7], but without any experimental verification. The Forge FEM software with an inbuilt modified Lemaitre damage model was used for predicting the Mannesmann effect in [8, 9]. The designed model, which was verified, simulated fracture dimensions not higher than $10 \%$ of the experimental ones. However, as it is shown in [10], the fracture simulated in [8,9] starts less than half way of the billet's diameter from the billet's end. It is shown experimentally in [11] that the fracture starts at half of the billet's diameter from the billet's end during two-high screw rolling. It is crucial to further investigate two-high screw rolling by means of computer simulation and experimental estimation to predict the fracture of billets.

The aim of the research was to estimate the effectiveness of different criteria for fracture prediction during computer simulation of two-high screw rolling of AISI 321 billets with different feed angles of rolls.

\section{Materials and methods}

Two-high screw rolling of AISI 321 billets in the MISIS130D mill [10] was performed to estimate a tendency for piercing through the appearance (or not appearance) of an axial fracture. The billets had a length of $300 \mathrm{~mm}$ and a diameter of $60 \mathrm{~mm}$. Screw rolling was done in one pass at $1200{ }^{\circ} \mathrm{C}$, the reduction was $17 \%$ (till $50 \mathrm{~mm}$ diameter). The rolls rotation frequency was 60 revolutions per minute. Screw rolling was done with $6^{\circ}, 12^{\circ}, 18^{\circ}$, and $24^{\circ}$ of the feed angle of rolls. After screw rolling was conducted, an axial fracture was observed for rolling with $6^{\circ}$ and $12^{\circ}$ of the feed angle of rolls (Fig. 1). Experimental rolling was simulated using QForm FEM software. 3D models of rolls, billet, guiding shoes, pusher and entry and exit holders were created using SolidWorks. The designed models were positioned into assembly, saved in .step format, and downloaded into the QShape geometry editor (Fig. 2).

Computer simulation was done in accordance with the experimental rolling parameters. The heat exchange between tolls and billet was set as "Simple" [12], there was no heat exchange between the pusher and the billet and the holders and the billet. The friction factor for the roll-billet was set as 3 (Siebel friction law), for the guiding shoe-billet, it was set as 0.3 , for the pusher-billet and the holder-billet, the friction factor was set as 0.1 .

\section{Results and discussion}

The estimation of fraction criteria changing at stationary and non-stationary stages for different rolls feed 

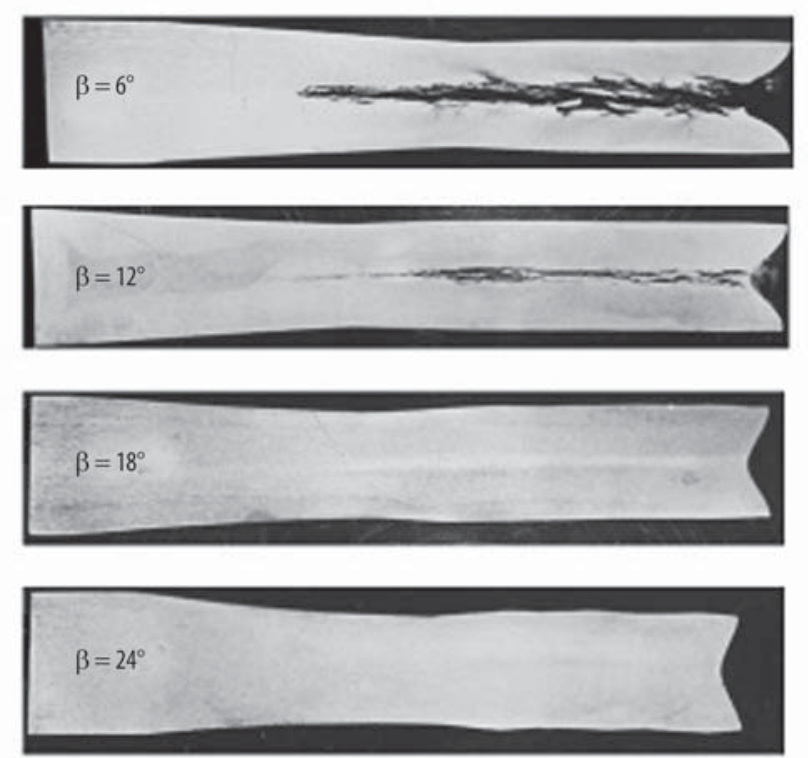

Fig. 1. Axial (longitudinal) fracture of the billets after two-high screw rolling at the rolls feed angle $(\beta)$ equal to $6^{\circ}, 12^{\circ}, 18^{\circ}$, and $24^{\circ}$

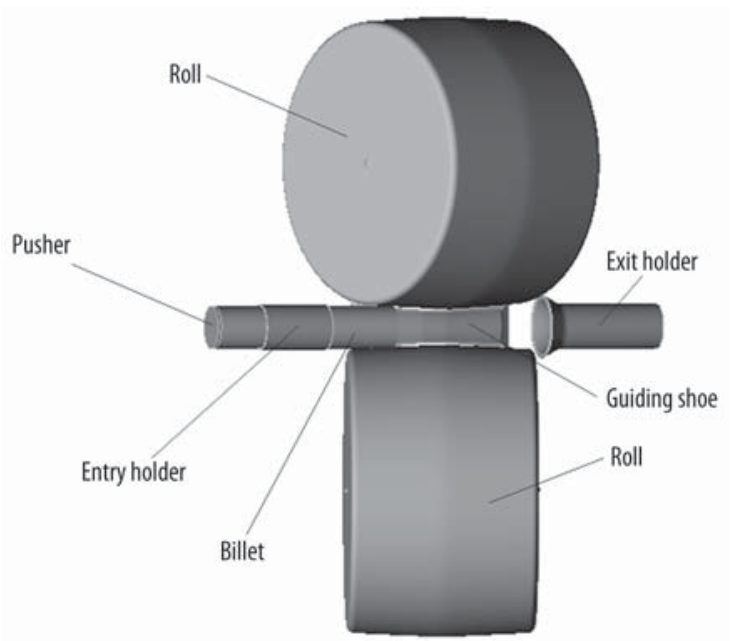

Fig. 2. QForm assemble for two-high screw rolling simulation with rolls feed angle equal to $18^{\circ}$ (one guiding shoe is not shown for convenience)

angles was done due to the results of computer simulation. The Normalized Cockroft-Latham (NCL), Oyane, Ayada and Brozzo damage criteria and triaxiality parameter were chosen for estimation. The NCL criterion value is calculated according to the formula:

$$
D=\int_{0}^{\bar{\varepsilon}} \frac{\sigma^{*}}{\bar{\sigma}} d \bar{\varepsilon},
$$

where $\bar{\varepsilon}$ is the accumulated strain, $d \bar{\varepsilon}$ is the accumulated strain increment, $\sigma^{*}$ is the maximum tensile stress; $\bar{\sigma}$ is the stress effective. The authors in [12] noticed that the NCL criterion is widely used, which is due to its simplicity, minimum material data necessary, and satisfactory accuracy during fracture prediction at different forming processes.
The Oyane criterion was used in [13] to predict a fracture during three-high screw rolling:

$$
I=\int_{0}^{\varepsilon_{e q \cdot f}}\left(A+\frac{\sigma_{m}}{\sigma_{e q}}\right) d \varepsilon \geq C,
$$

where $A$ and $C$ are the material' $s$ constants; $\sigma_{m}$ is the mean stress; $\sigma_{e q}$ is the stress effective; $\varepsilon_{e q . f}$ is the accumulated strain; $d \varepsilon$ is the accumulated strain increment.

The authors of [14] posit that the Ayada and Brozzo criteria are among the most often used. The Ayada criterion value is calculated according to the formula:

$$
I=\int_{0}^{\varepsilon} \eta d \varepsilon,
$$

where $\varepsilon$ is the strain effective; $\eta$ is the stress triaxiality [12]. The Brozzo criterion value is calculated according to the formula:

$$
I=\int_{0}^{\varepsilon} \frac{2 \sigma_{1}}{3\left(\sigma_{i}-\sigma_{m}\right)} d \varepsilon,
$$

where $\sigma_{1}$ is the maximum principle stress; $\sigma_{i}$ is the stress effective; $\sigma_{m}$ is the mean stress; $\varepsilon$ is the strain effective.

It is shown in $[15,16]$ that the mean stress - stress effective ratio (the authors of [12] name this ratio as a normalized mean stress, the same ration when multiplied by a constant named a rigidity coefficient under stress condition [12, 15-17]) provides a satisfactory fracture prediction during screw rolling processes. Using this ratio allows predicting the fracture location and identifying the main process parameters such as the number of rolls, the feed angle value, and some other parameters that affect the fracture, its value and location. The most known name for this ratio is "stress triaxiality" or "triaxiality" $[8,12$, $14-16,18]$. The calculation of this value is realized in the QForm software:

$$
\eta=\frac{\sigma_{m}}{\bar{\sigma}},
$$

where $\sigma_{m}$ is the mean stress; $\bar{\sigma}$ is the stress effective.

The computer simulation results allowed estimation of changing of the chosen criteria (formulae (1)-(5)) for 6 points located along the billet's radius with $4 \mathrm{~mm}$ step. The point tracking was done for radii located in the cross section at $25 \mathrm{~mm}$ form the billet's end (non-stationary stage of screw rolling) and in the cross section in the middle of the billet (stationary stage of screw rolling). The data with the criteria values were exported from QForm into Microsoft Excel and the graphics were built using second degree polynomial trend lines to show how the criteria values change along the billet's radius at stationary and non-stationary stages (Fig. 3 and Fig. 4).

According to Figs. 3 and 4, changing of the NCL, Oyane, Ayada and Brozzo damage criteria show that the fracture is more probable on the surface of the billet rather than in the billet's center where the feed angle is 6 degrees. This contradicts the experimental results because there was an axial fracture. Fig. 3, $d$ shows that for the Ayada criterion, the risk of a fracture at $12^{\circ}$ and $18^{\circ}$ of the feed 

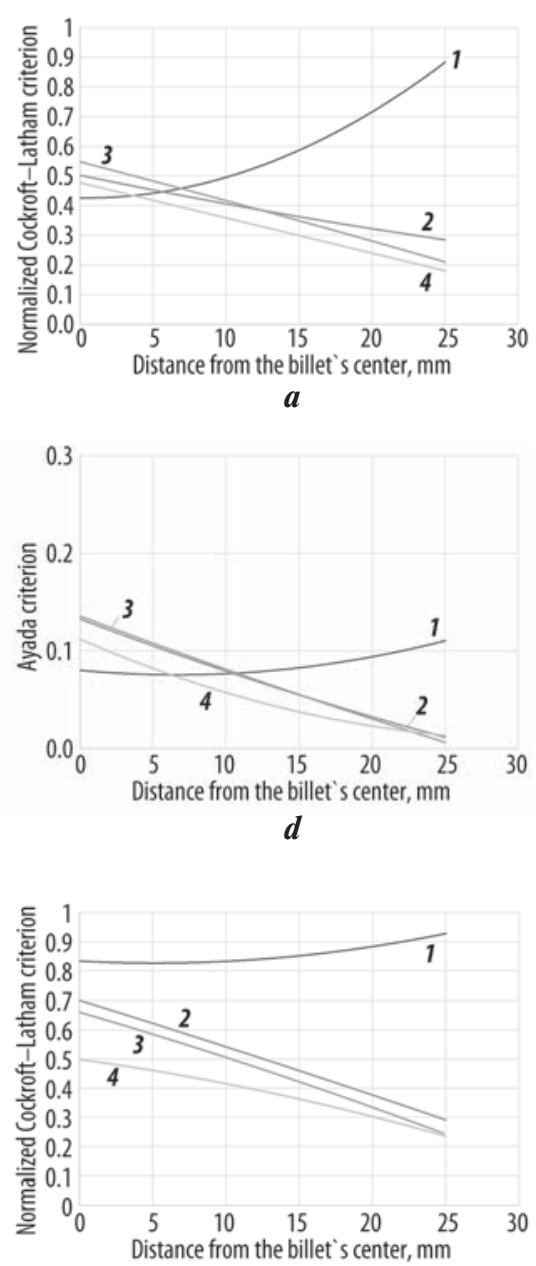

$\boldsymbol{a}$

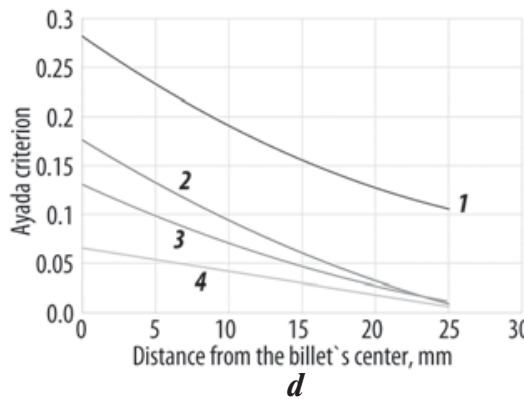

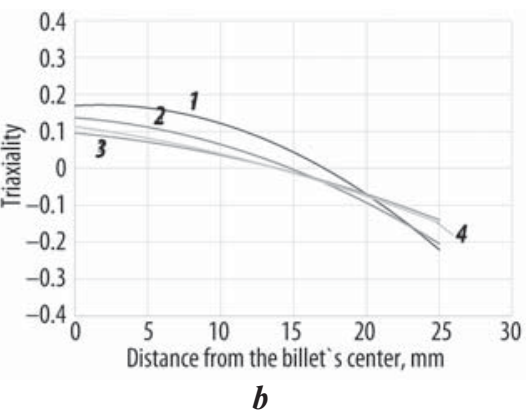
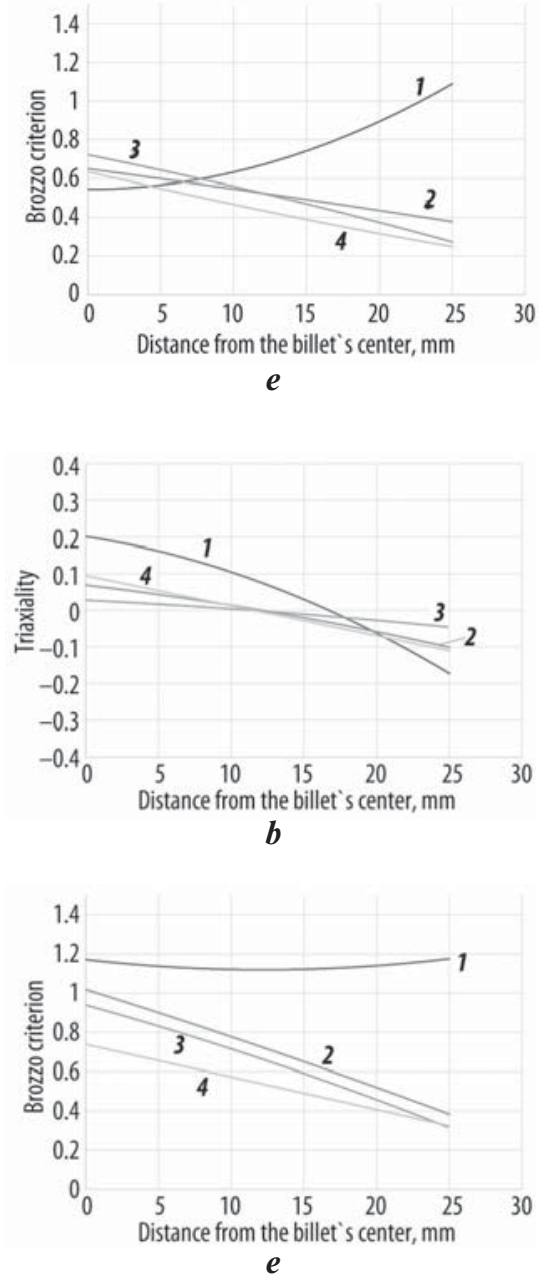

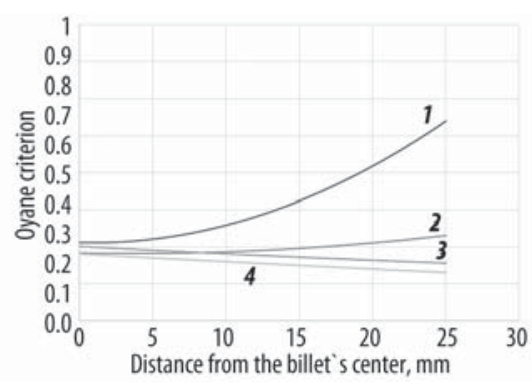

c

Fig. 3. Changing of the NCL (a), Triaxiality (b), Oyane (c), Ayada (d) and Brozzo (e) criteria at the non-stationary stage of two-high screw rolling at $6^{\circ}(1), 12^{\circ}(2), 18^{\circ}(3)$ and $24^{\circ}$ (4) of the rolls feed angle

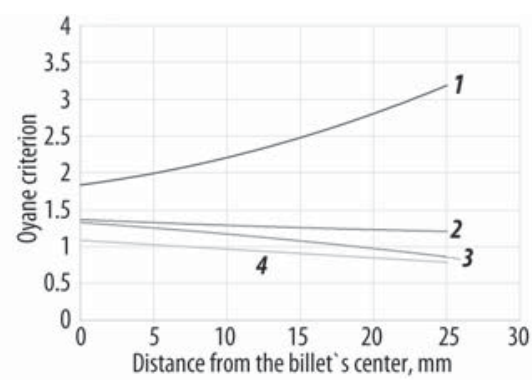

c

Fig. 4. Changing of the NCL (a), Triaxiality (b), Oyane (c), Ayada (d) and Brozzo (e) criteria at the stationary stage of two-high screw rolling at $6^{\circ}$ (1), $12^{\circ}(2), 18^{\circ}$ (3) and $24^{\circ}$ (4) of the rolls feed angle

\begin{tabular}{|c|c|c|c|c|c|c|}
\hline \multicolumn{7}{|c|}{$\begin{array}{l}\text { Mean values of the NCL, Triaxiality, Oyane, Ayada and Brozzo damage criteria at the non-stationary and stationary stages and different } \\
\text { rolls feed angle values }\end{array}$} \\
\hline Rolls feed angle value, $^{\circ}$ & Screw rolling stage & $\mathrm{NCL}$ & Triaxiality & Oyane & Ayada & Brozzo \\
\hline \multirow[t]{2}{*}{6} & Non-stationary & 0.571 & 0.052 & 1.571 & 0.085 & 0.721 \\
\hline & Stationary & 0.857 & 0.048 & 2.402 & 0.182 & 1.142 \\
\hline \multirow[t]{2}{*}{12} & Non-stationary & 0.385 & -0.002 & 0.995 & 0.068 & 0.513 \\
\hline & Stationary & 0.505 & -0.006 & 1.284 & 0.086 & 0.718 \\
\hline \multirow[t]{2}{*}{18} & Non-stationary & 0.388 & 0.002 & 0.431 & 0.072 & 0.516 \\
\hline & Stationary & 0.450 & -0.007 & 1.103 & 0.062 & 0.629 \\
\hline \multirow[t]{2}{*}{24} & Non-stationary & 0.322 & -0.006 & 0.771 & 0.052 & 0.426 \\
\hline & Stationary & 0.374 & -0.012 & 0.931 & 0.035 & 0.523 \\
\hline
\end{tabular}

angle is almost the same. For a more detailed analysis, the mean values of the criteria for different screw rolling stages and rolls feed angle values were calculated (Table) for the points being tracked.
According to [19], the range of strains and stresses at two-high screw rolling of the AISI 321 steel billet at the stationary stage is less compared with the non-stationary stage. It suggests lower non-uniformity of strains 
and stresses at the stationary stage and, hence, a lower risk of a fracture. This trend is supported by the experiments (see Fig. 1): while moving from the billet's end (non-stationary stage) towards its middle (stationary stage), the fracture volume decreases. Hence, the mean values of the criteria at the stationary stage should be less compared with those at the non-stationary stage. The described trends are fully supported only by triaxiality changing (Table). A partial correspondence to the above stated trends is for the Ayada damage criterion ( $18^{\circ}$ and $24^{\circ}$ rolls feed angle).

The diagrams in Fig. 3 and Fig. 4 and Table show that in the aggregate all the chosen items, except triaxiality parameter, are the least effective when the rolls feed angle is 6 degrees.

Total or partial inefficiency of the Oyane, Ayada, Brozzo and NCL criteria could be due to using the increment of strain effective or accumulated strain in the formulas used to calculate these criteria values. Both specified parameters have their maximum on the surface of the billet rather than in the center during two-high screw rolling [20], which results in higher criteria values on the billet's surface compared with its center (see Fig. 3 and Fig. 4).

\section{Conclusions}

Two-high screw rolling with $6^{\circ}, 12^{\circ}, 18^{\circ}$, and $24^{\circ}$ of the rolls feed angle was simulated using the QForm FEM software to predict a possible fracture using different damage criteria. The computer simulation results were compared with the experimental data. It was established, that fraction risk, fraction character and its dependence on the rolls' feed angle are most effectively estimated by the distribution of triaxiality parameter. As a result of this, it is expected to be efficient to use such tools as Kolmogorov damage model $[17,21]$ or Bao-Wierzbicki damage model [22] which are designed using triaxiality parameter. The Normalized Cockroft-Latham, Oyane, Ayada, and Brozzo damage criteria are ineffective for fracture prediction at screw rolling.

\section{REFERENCES}

1. Shatalov R. L., Medvedev V. A. Regulation of the Rolling Temperature of Blanks of Steel Vessels in a Rolling-Press Line for the Stabilization of Mechanical Properties. Metallurgist, 2020. Vol. 63(9-10). pp. 1071-1076.

2. Shatalov R. L., Medvedev V. A., Zagoskin E. E. Determination of mechanical properties of steel thin-walled vessels by hardness after hot screw rolling with subsequent stamping and quenching. Chernye metally. 2019. No. 7. pp. 36-40.

3. Naizabekov A., Arbuz A., Lezhnev S., Panin E., Volokitina I. The development and testing of a new method of qualitative analysis of the microstructure quality, for example of steel AISI 321 subjected to radial shear rolling. Physica Scripta. 2019. Vol. 94 (10). p.105702.

4. Protasyev V. B., Batova N. N. Design of rolls for hot cross-helical rolling of billets without defetcs in the axial zone. Chernye metally. 2020 No. 3. pp. 42-47.
5. Teterin P. K. Theory of screw rolling. Moscow. Metallurgiya. 1973, $368 \mathrm{p}$.

6. Joun M., Lee J., Cho J., Jeong S., Moon H. Quantitative Study on Mannesmann Effect in Roll Piercing of Hollow Shaft. Procedia Engineering, 2014. Vol. 81, pp. 197-202.

7. Berazategui D. A., Cavaliere M. A., Montelatici L., Dvorkin E. N. On the modelling of complex 3D bulk metal forming processes via the pseudo-concentrations technique. Application to the simulation of the Mannesmann piercing process. International Journal for Numerical Methods in Engineering. 2006. Vol. 65. No 7. pp. 1113-1144.

8. Ghiotti A., Fanini S., Bruschi S., Bariani P. Modelling of the Mannesmann effect. CIRP Annals. 2009. Vol. 58, Iss. 1. pp. 255-258.

9. Fanini S., Bruschi S., Ghiotti A. Mannesmann fracture prediction in tube piercing. Computational Plasticity X-Fundamentals and Applications. 10th International Conference on Computational Plasticity, COMPLAS X; Barcelona; Spain; 2 September 2009 - 4 September 2009. 4 p.

10. Skripalenko M. M., Romantsev B. A., Galkin S. P., Skripalenko M. N., Kaputkina L. M., Huy T. B. Prediction of the Fracture of Metal in the Process of Screw Rolling in a Two-Roll Mill. Metallurgist. 2018. Vol. 61. No. 11-12. pp. 925-933.

11. Nikulin A. N. Screw rolling. Stresses and strains. Moscow. Metallurgizdat. 2015. $380 \mathrm{p}$

12. Vlasov A. V., Stebunov S. A., Evsyukov S. A., Biba N. V., Shitikov A. A. Finite element method simulation of forging and die forging: school-book. Izdatelstvo MGTU imeni N. E. Baumana. 2019. 383 p.

13. Li S. Z., Meng W. H., Hu L. W., Ding B. Research on the tendency of inner crack during 3-roll skew rolling process of round billets. Advanced Materials Research. 2011. Vol. 145. pp. 238-242.

14. Pater Z., Tomczak J., Bulzak T.. Establishment of a new hybrid fracture criterion for cross wedge rolling. International Journal of Mechanical Sciences. 2020. Vol. 167. February. 105274.

15. Skripalenko M. M., Galkin S. P., Her Jae Sung, Romantsev B. A., Tran Ba Huy, Kaputkina L. M., Skripalenko M. N., Sidorov A. A. Prediction of Potential Fracturing During Radial-Shear Rolling of Continuously Cast Copper Billets by Means of Computer Simulation. Metallurgist. 2019. Vol. 62. No. 9-10. pp 849-856.

16. Skripalenko M. M., Galkin S. P., Karpov B. V., Romantsev B. A., Kaputkina L. M., Danilin A. V., Skripalenko M. N., Patrin P. V. Forming Features of Titanium Alloy Billets After Radial-Shear Rolling. Materials 2019. No. 12 (19). 3179.

17. Kolmogorov V. L. Metal forming mechanics. Ekaterinburg. Izdatelstvo Uralskogo GTU. 2001. 836 p.

18. Fanini S. Modelling of the Mannesmann Effect in Tube Piercing, Ph.D. Thesis, University of Padua, 2008.

19. Skripalenko M. M., Romantsev B. A., Kaputkina L. M., Galkin S. P., Skripalenko M. N., Cheverikin V. V. Study of Transient and Steady-State Stages During Two-High and ThreeHigh Screw Rolling of a 12Kh18N10T Steel Workpiece. Metallurgist. 2019. Vol. 63. pp. 366-375.

20. Skripalenko M. M., Romantsev B. A., Galkin S. P., Kaputkina L. M., Skripalenko M. N. Study of Strain and Structural Peculiarities in Different Stages of Two- and Three-High Screw Rolling. Steel in Translation. 2019. Vol. 49 (10), pp. 709-715.

21. Kolmogorov V. L. Stress, strain, fracture. Moscow. Metallurgy. 1970. 229 p.

22. Wierzbicki T., Bao Y., Lee Y.-W., Bai Y. Calibration of seven fracture models. International Journal of Mechanical Sciences. 2005. Vol. 47. pp. 719-743. 